OPEN ACCESS

Edited by:

Soohyun Kim,

Konkuk University, South Korea

Reviewed by:

Jaya Talreja,

Wayne State University School of Medicine, United States

Anna Maria Piccinini, University of Nottingham,

United Kingdom

${ }^{*}$ Correspondence:

Jeon-Soo Shin

jsshin6203@yuhs.ac

Specialty section:

This article was submitted to

Inflammation

a section of the journal

Frontiers in Immunology

Received: 13 March 2020

Accepted: 22 May 2020

Published: 23 June 2020

Citation:

Kim HS, Han M, Park IH, Park CH,

Kwak MS and Shin J-S (2020)

Sulfatide Inhibits HMGB1 Secretion by Hindering Toll-Like Receptor 4

Localization Within Lipid Rafts.

Front. Immunol. 11:1305

doi: 10.3389/fimmu.2020.01305

\section{Sulfatide Inhibits HMGB1 Secretion by Hindering Toll-Like Receptor 4 Localization Within Lipid Rafts}

\author{
Hee Sue Kim ${ }^{1,2}$, Myeonggil Han ${ }^{1,2}$, In Ho Park ${ }^{3,4}$, Cheol Ho Park ${ }^{1}$, Man Sup Kwak ${ }^{1,4}$ and \\ Jeon-Soo Shin $1,2,3,4 *$ \\ ${ }^{1}$ Department of Microbiology, Yonsei University College of Medicine, Seoul, South Korea, ${ }^{2}$ Brain Korea 21 PLUS Project for \\ Medical Science, Yonsei University College of Medicine, Seoul, South Korea, ${ }^{3}$ Severance Biomedical Science Institute, \\ Yonsei University College of Medicine, Seoul, South Korea, ${ }^{4}$ Institute for Immunology and Immunological Diseases, Yonsei \\ University College of Medicine, Seoul, South Korea
}

The high mobility group box 1 (HMGB1) is a well-known late mediator of sepsis, secreted by multiple stimuli, involving pathways, such as the mitogen-activated protein kinase (MAPK) and nuclear factor kappa B (NF-kB) pathways, and reactive oxygen species (ROS) under inflammation. Sulfatide, in contrast, is a sphingolipid commonly found in myelin sheets with a disputed immunological role. We sought to determine the immunological characteristics of sulfatide in the periphery by analyzing the secretion of HMGB1 triggered by lipopolysaccharide (LPS) stimulation in Raw 264.7 cells. Suppression of HMGB1 secretion by inhibiting its cytosolic translocation was observed after pre-treatment with sulfatide before LPS stimulation. Further analysis of the downstream molecules of toll-like receptor (TLR) signaling revealed suppression of c-Jun $\mathrm{N}$-terminal kinase (JNK) phosphorylation and p65 translocation. LPS-mediated ROS production was also decreased when sulfatide pre-treatment was provided, caused by the down-regulation of the phosphorylation of activators, such as IRAK4 and TBK1. Investigation of the upstream mechanism that encompasses all the aforementioned inhibitory characteristics unveiled the involvement of lipid rafts. In addition to the co-localization of biotinylated sulfatide and monosialotetrahexosylganglioside, a decrease in LPS-induced co-localization of TLR4 and lipid raft markers was observed when sulfatide treatment was given before LPS stimulation. Overall, sulfatide was found to exert its anti-inflammatory properties by hindering the co-localization of TLR4 and lipid rafts, nullifying the effect of LPS on TLR4 signaling. Similar effects of sulfatide were also confirmed in the LPS-mediated murine experimental sepsis model, showing decreased levels of serum HMGB1, increased survivability, and reduced pathological severity.

Keywords: sulfatide, HMGB1, TLR4, lipid raft, sepsis, NF-кB, ROS

\section{INTRODUCTION}

Approximately 45 years have passed since the HMGB1 protein, an abundant nuclear protein and a well-defined danger-associated molecular pattern (DAMP) molecule, was first purified (1). Since its discovery, HMGB1 has been discussed in various contexts. Nuclear HMGB1 is well-known for its chaperone-like functions, playing a role in deoxyribonucleic acid (DNA) 
unwinding (2) and DNA synthesis (3) by binding to DNA in a sequence-independent manner (4) and in the structuring of chromatin (5). In contrast, research regarding cytosolic HMGB1 is still in its relatively early stages, revealing its role in autophagy regulation (6) and unconventional protein secretion (7).

HMGB1 can be either passively released through nonapoptotic cell death, such as in necrotic cells (8), or actively secreted through multiple pathways, such as in inflammasomemediated release (9). In this paper, we intend to limit the scope to active secretion of HMGB1, triggered by inflammatory signals transduced by toll-like receptor (TLR)-related signaling. When TLRs are stimulated by their ligands, NF-кB (10) and MAPK (10-12) are responsible for the translocation and secretion of these receptors to the extracellular space. Our research concentrates on TLR4, a member of the TLR family, which recognizes lipopolysaccharides (LPS), and its mechanism of action regarding the active secretion of HMGB1. Under physiological conditions, bacterial LPS, which normally forms a micelle, is recognized by the LPS-binding protein (LBP), which facilitates its monomerization by CD14 (13). The LPSLBP complex, now bound to CD14, is then transferred to the myeloid differentiation protein-2 (MD-2)-TLR4 complex (14). This complex then forms a dimer, completing its activation process. TLR4 dimers, however, require the formation of a lipid raft, a special nano-scale membrane structure consisting of various lipids (15). TLR4, which contains lipid-binding motifs, is attracted and can readily form a dimer within the lipid rafts, providing a platform on which the TLR4s can be within closer proximity (16).

Most studies addressing the immunological role of HMGB1 have focused on the role of extracellular HMGB1 as a DAMP molecule and its chemokine-like behavior. Depending on its redox status, HMGB1 exerts different characteristics: 1) as a thiol isoform, in which all of the three active cysteine residues (Cys23, 45, and 106) are in free-thiol(-SH) form, HMGB1 binds to C-X-C motif ligand 12 (CXCL12) and shows chemokine-like activity, recruiting immune cells to the site of inflammation (17); 2) the disulfide isoform of HMGB1, which possesses one intra-molecular disulfide bond between the two cysteine molecules Cys23 and Cys45, exerts cytokine-like activity, activating macrophages and lymphocytes (18-20); 3 ) the oxidized isoform of HMGB1, containing fully oxidized cysteine residues ($\mathrm{SOOOH})$ is considered immunologically inert $(21,22)$. In sepsis, extracellular HMGB1 is known to be released in its reduced form (23); it is considered a potent pro-inflammatory cytokine (24) and a promising therapeutic target in clinical studies $(25,26)$.

Sulfatide, also known as 3-O-sulfogalactosylceramide, is a lipid commonly found in the myelin sheath in both the central and peripheral nervous system (27). First isolated and partially characterized over 40 years ago (28), sulfatide was suggested to play a varying role in physiological functions, ranging from myelination of nerves $(29,30)$ to insulin secretion (3134). Similar to HMGB1, intracellular (or membrane-bound) sulfatide and extracellular sulfatide play different roles. While the intracellular (or membrane-bound) form performs the abovementioned functions, extracellular sulfatide can bind to selectins to cause hemostasis (35) or metastasis of tumors
(36) or bind to CD1d activating natural killer T (NKT) cells with various anti-inflammatory abilities (37-41). Although most papers discussing the anti-inflammatory functions of sulfatide emphasize on NKT cells, a report suggested that sulfatide may have a direct effect on brain-resident immune cells, causing inflammation (42). This discrepancy between immune cells residing in the central or peripheral nervous system led us to investigate the direct effect of sulfatide in peripheral immune cells, namely the macrophages.

In this study, we aimed to elucidate the effect of sulfatide in the context of innate immunity by investigating its effect on HMGB1 secretion under LPS stimulus and discuss the specific molecules involved in the process.

\section{MATERIALS AND METHODS}

\section{Cell Culture and Treatment Reagents}

Raw 264.7 cells were cultured in Dulbecco's Modified Eagle's Medium supplemented with $10 \%$ heat-inactivated fetal bovine serum (Gibco, Waltham, MA, USA), $100 \mu \mathrm{g} / \mathrm{mL}$ of penicillin, and $100 \mu \mathrm{g} / \mathrm{mL}$ of streptomycin (Sigma, Saint Louis, MO, USA). Treatment was performed after allowing the cells to adapt to Opti-MEM (Gibco) for $2 \mathrm{~h}$, after which the media was replaced.

LPS (Escherichia coli O111:B4; > $3 \times 10^{6}$ EU/mL; Sigma), sulfatide (Bovine; brain; Matreya, State College, PA, USA), 18:0(2R-OH) sulfogalactosylceramide (synthetic; Avanti, Alabaster, AL, USA), C24:0 mono-sulfogalactosylceramide (synthetic; Avanti), C24:0 mono-sulfogalactosylceramide (synthetic; Avanti), galactosylceramide (Bovine; Matreya), and ceramide (Bovine; Matreya) were used as indicated in the figures. All experiments were performed using vehicle as a negative control.

\section{Bone Marrow-Derived Macrophage (BMDM) Preparation}

Wild-type C57BL/6 mice obtained from Orient Bio (Seongnam, Gyeonggi-do, South Korea) were housed in a SPF-grade facility with controlled temperature, humidity, and light. For all experiments, 8 -week old female mice with approximate body weight of $20 \mathrm{~g}$ were used. The animals were ethically sacrificed, and the femur and tibia were extracted. Bone marrow was collected via warm, serum-free DMEM lavage until no remaining bone marrow was visible. Bone marrow was collected and filtered through cell strainer with $40 \mu \mathrm{m}$ pore (SPL, Pocheon-si, Gyeonggi-do, South Korea) to remove any undesirable debris and washed with excessive media to further remove unfiltered debris. The resulting cells were plated to $100 \mathrm{~mm}$ cell culture-treated dish (Corning, Oneonta, NY, USA), and then differentiated using $20 \mathrm{ng} / \mathrm{mL}$ GM-CSF in complete medium for 7 days to yield BMDMs.

\section{Sample Preparation (Culture Media)}

Culture media after treatment were collected after $24 \mathrm{~h}$ to compare HMGB1 secretion between groups. Culture media were then centrifuged at $3500 \times \mathrm{g}$ for $5 \mathrm{~min}$ to remove any cell debris. The supernatant was collected for trichloroacetic 
acid (TCA)/acetone precipitation. Then, $10 \%$ by volume of icecold TCA was added to the samples and mixed by inverting. After incubating overnight at $-20^{\circ} \mathrm{C}$, the samples were thawed and centrifuged at $20000 \times \mathrm{g}$ for $90 \mathrm{~min}$. Supernatants were then discarded. The remaining pellets were washed with $-20^{\circ} \mathrm{C}$ acetone by vortexing vigorously and left overnight at $-20^{\circ} \mathrm{C}$. Samples were centrifuged at $20000 \times \mathrm{g}$ for $90 \mathrm{~min}$, and the resulting supernatants were removed. The remaining pellets were then dried and boiled with $2 \mathrm{X}$ sample buffer.

\section{Sample Preparation (Whole Cell Lysate)}

Cells were harvested by scraping using cold Dulbecco's phosphate buffered saline (PBS) after the indicated time periods; they were then collected by centrifuging at $3000 \times \mathrm{g}$ for $5 \mathrm{~min}$. Supernatants were discarded, and radioimmunoprecipitation (RIPA) buffer was added before sonication. Lysed cells were centrifuged at $20000 \times \mathrm{g}$ for $10 \mathrm{~min}$ to remove any debris. The resulting whole cell lysates were collected, and protein concentration was quantified using the bicinchoninic acid (BCA) assay. The cell lysates were then prepared by heating to $65^{\circ} \mathrm{C}$ for $10 \mathrm{~min}$ after adding sample buffer to minimize the loss of phosphorylated protein to beta-elimination.

\section{Western Blot}

SDS-PAGE was performed on samples prepared via the abovementioned methods, and proteins were transferred to a polyvinylidene difluoride (PVDF) membrane for western blotting. Transferred membranes were blocked using 5\% skimmed milk. Primary antibodies for HMGB1 (Abcam; Cambridge, UK), JNK (phospho- and whole; Cell Signaling Technology; Danvers, MA, USA), ERK1/2 (phospho- and whole; Cell Signaling Technology), p38 (phospho- and whole; Cell Signaling Technology), phospho-IкB $\alpha$ (Cell Signaling Technology), phospho-IRAK4, phospho-TBK1 (Cell Signaling Technology), caveolin 1 (Merck; Darmstadt, Germany), TLR4 (Santa Cruz; Dallas, TX, USA), and $\beta$-actin (Santa Cruz) were diluted in $5 \%$ skimmed milk solution and incubated overnight at $4{ }^{\circ} \mathrm{C}$. After extensive washing, the corresponding secondary antibody solutions were incubated for $1 \mathrm{~h}$ at room temperature $\left(20 \sim 25^{\circ} \mathrm{C}\right)$. The membranes were then washed, and signals were detected using enhanced chemiluminescence substrate solution (Gendepot; Katy, TX, USA) and X-ray film (AGFA; Mortsel, Belgium). Membranes were stripped using stripping solution (BioMax, Seoul, South Korea) for re-blotting, as necessary. Densitometry analysis was performed using Image J.

\section{Immunofluorescence}

Raw 264.7 cells were seeded in 4-well chambered glass slides coated with poly-L-lysine (Sigma). Treatment dosage for LPS was increased to $200 \mathrm{ng} / \mathrm{mL}$ to facilitate visualization via immunofluorescence, and sulfatide dosage was adjusted accordingly to maintain molar ratio. Treatment was performed for the duration indicated in Figure Legends. After treatment, cells were then fixed with $4 \%$ paraformaldehyde overnight in $4^{\circ} \mathrm{C}$. On the subsequent day, the cells were washed with PBS and permeabilized with $1 \%$ Triton X-100 and blocked with bovine serum albumin (BSA). Primary antibodies anti-p65 (Santa
Cruz) or anti-HMGB1 (Abcam) were diluted in BSA solution and left to incubate overnight at $4{ }^{\circ} \mathrm{C}$. After thorough washing, the respective secondary antibodies conjugated with Alexa Fluor 488 (Invitrogen; Waltham, MA, USA) were diluted in BSA solution and incubated at $37^{\circ} \mathrm{C}$ for $45 \mathrm{~min}$. Slides were then washed, dried, and mounted using mounting medium containing 4',6-diamidino-2-phenylindole (DAPI; Vector). Sealed slides were observed via FV1000 confocal microscopy (Olympus). Localization of sulfatide was determined by treating Raw 264.7 cells with biotin-sulfatide and staining them with streptavidinAlexa Fluor 488 (Invitrogen). Localization of TLR4 was detected using mouse anti-TLR4 antibodies (Invitrogen).

\section{ROS Detection}

Raw 264.7 cells were pre-treated with either vehicle control or $20 \mu \mathrm{M}$ of sulfatide and with vehicle control or $100 \mathrm{ng} / \mathrm{mL}$ of LPS for $1 \mathrm{~h}$. The treatment medium was removed, and culture dishes were washed twice with warm culture medium. H2DCFDA (Thermo Fisher; Waltham, MA, USA) was treated as per the manufacturer's instructions. Cells were viewed under a fluorescence microscope. For flow cytometric analysis of ROS levels, the cells were detached before H2-DCFDA treatment.

\section{Lipid Raft Staining}

Raw 264.7 cells were seeded in 4-well chambered glass slides coated with poly-L-lysine (Sigma). Treatment dosage for LPS was increased to $1 \mu \mathrm{g} / \mathrm{mL}$ to maximize lipid raft formation and facilitate visualization via immunofluorescence, and sulfatide dosage was adjusted accordingly to maintain molar ratio. Treatment was performed for the duration indicated in Figure Legends. After treatment, the cells were then washed once with $4^{\circ} \mathrm{C}$ complete growth medium. Washed cells were incubated in cholera toxin B-Alexa Fluor 549 (Invitrogen) staining solution, prepared in $4^{\circ} \mathrm{C}$ complete growth medium. Cells were washed with ice-cold PBS three times and fixed with ice-cold 4\% paraformaldehyde for $15 \mathrm{~min}$.

\section{Lipid Raft Isolation}

Raw 264.7 cells were treated with reagents for $8 \mathrm{~min}$ as indicated in the legends, and cells were briefly washed three times with ice-cold PBS to halt the internalization of lipid rafts. Cells were then lysed using the ice-cold buffer provided by Caveolea/Rafts Isolation Kit (Merck) supplemented with Triton X-100. Lysates then underwent ultracentrifugation with OptiPrep ${ }^{\mathrm{TM}}$ density gradient, provided by the aforementioned kit, and nine fractions were collected. Collected fractions were then supplemented with $1 \%$ SDS to assist complete dissociation of the protein from the lipids. Treated samples were concentrated using TCA/Acetone and analyzed by immunoblotting.

\section{Animal Experiments}

Wild-type C57BL/6 mice obtained from Orient Bio (Seongnam, South Korea) were housed in a SPF-grade facility with controlled temperature, humidity, and light. For all experiments, 8week old female mice were used. For serum collection, mice were anesthetized using an isoflurane-oxygen mixture, and combinations of PBS, LPS (3 mg/kg), or sulfatide (25 nmol) 
were injected with a total of $100 \mu \mathrm{L}$ injection volume, intraperitoneally. The animals were allowed $60 \mathrm{~min}$ between injections to fully recover from the effects of anesthesia. Serum samples were collected after $18 \mathrm{~h}$. Survival rate was measured by following the same procedure as mentioned above, with increased doses of LPS and sulfatide injection (to $20 \mathrm{mg} / \mathrm{kg}$ and 175 nmol, respectively). Mice were checked twice every day and observed until completion. Survival data were then analyzed through Kaplan-Meier survival analysis. Pathological scores were obtained using the scoring regimen described by Shrum et al. (43), and the obtained scores were then analyzed through ANOVA and Dunnett's multiple comparison

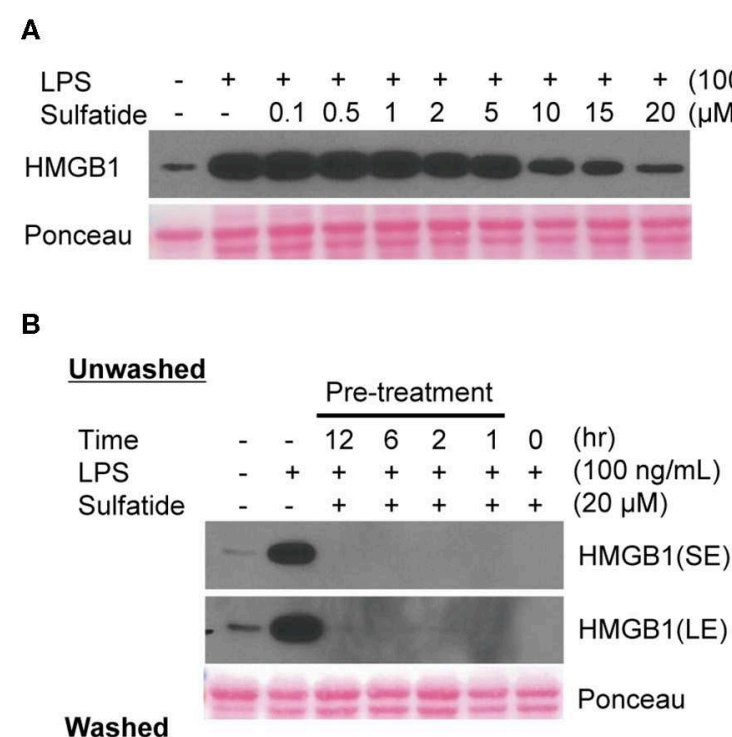

Washed

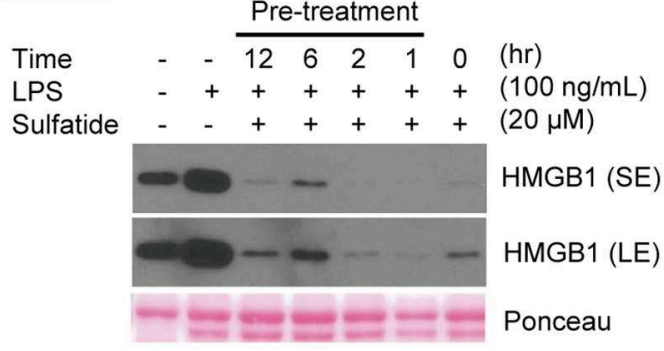

D
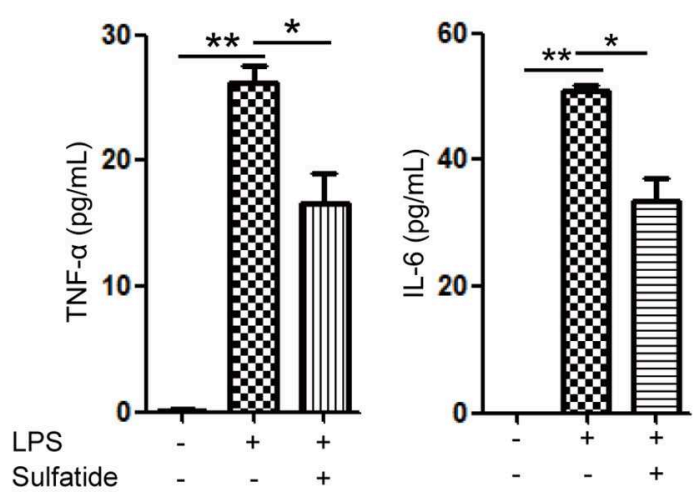

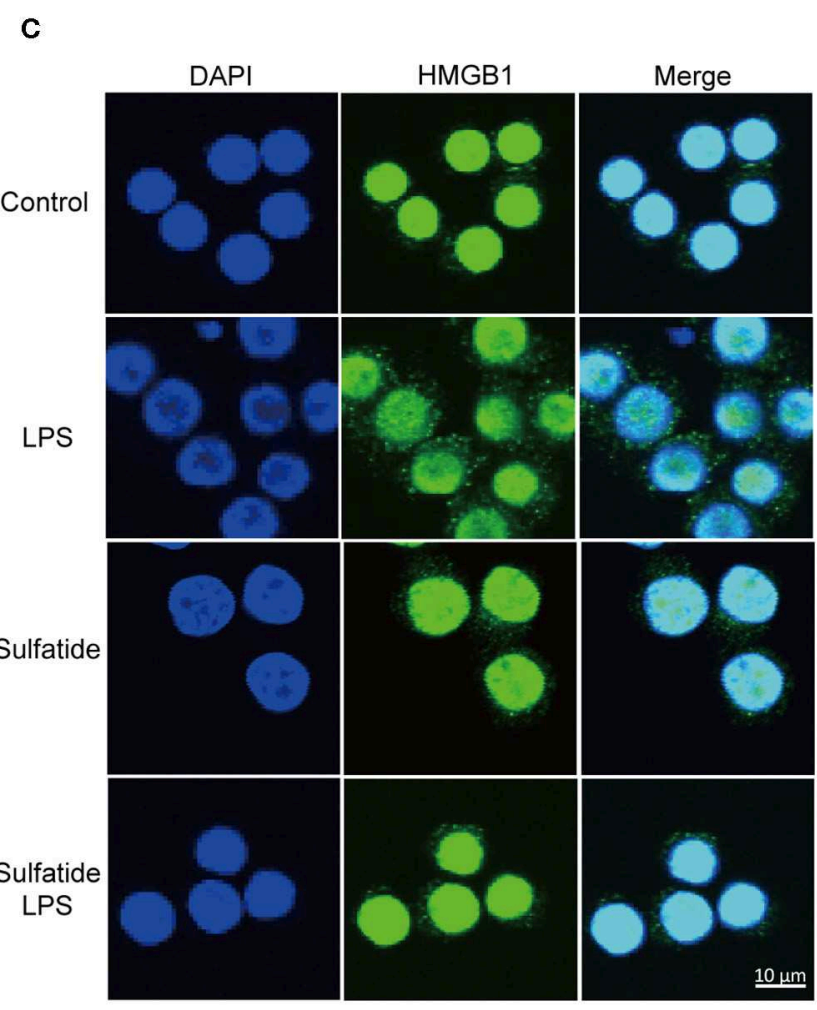

FIGURE 1 | Sulfatide inhibits HMGB1 translocation and release in Raw 264.7 cells. (A) Dose-dependency of sulfatide regarding HMGB1 secretion was accessed $24 \mathrm{~h}$ after LPS treatment. Varying dosage of sulfatide was treated 10 min prior to LPS treatment. (B) Efficacy of sulfatide pre-treatment for indicated time on HMGB1 secretion and its effect after removal of sulfatide was observed. Washed cells received two $36^{\circ} \mathrm{C}$ PBS wash to remove the residual sulfatide prior to LPS treatment, whereas unwashed cells were left unperturbed. (SE, Short Exposure; LE, Long Exposure) (C) Raw 264.7 cells received vehicle control, LPS $200 \mathrm{ng} / \mathrm{mL}$, sulfatide $40 \mu \mathrm{M}$ only, or $10 \mathrm{~min}$ of sulfatide $40 \mu \mathrm{M}$ pre-treatment, followed by LPS $200 \mathrm{ng} / \mathrm{mL}$ for $6 \mathrm{~h}$. Cells were fixed for analysis by immunofluorescence, as described in the Methods section. In total, 100 cells were counted, and those containing HMGB1 signals in the cytoplasm were counted as positive. (D) Culture media were analyzed by ELISA for TNF- $\alpha$ and IL-6 titer. Cells were treated with vehicle control (PBS with DMSO), LPS $100 \mathrm{ng} / \mathrm{mL}$, or 10 min of sulfatide $20 \mu \mathrm{M}$ pre-treatment, followed by LPS $100 \mathrm{ng} / \mathrm{mL}$. Graphs show the mean value and error bars of three independent experiments performed. ${ }^{*} p<0.01,{ }^{* *} p<0.001$. 
test. All experiments were conducted according to procedures approved by the Institutional Animal Care and Use Committee of the Yonsei Laboratory Animal Research Center (YLARC, 2015-0275).

\section{Enzyme-Linked Immunosorbent Assay (ELISA)}

Tumor necrosis factor $\alpha$ (TNF- $\alpha$ ) and interleukin-6 (IL6) ELISA were performed using Raw 264.7 cell culture medium. Cells were treated with vehicle control (negative control), $100 \mathrm{ng} / \mathrm{mL}$ LPS, and sulfatide $20 \mu \mathrm{M}$, followed by LPS $100 \mathrm{ng} / \mathrm{mL}$. Culture media were collected after $12 \mathrm{~h}$ of treatment and centrifuged to remove any cell debris. ELISA was performed with the resulting supernatant following the manufacturer's instructions (Invitrogen). Serum obtained from murine experimental sepsis models was analyzed for HMGB1 levels with a HMGB1 ELISA kit (IBL International), following the manufacturer's instructions.

\section{Statistical Analysis}

Unless specified otherwise, statistical analysis of experimental data present in this paper were performed with Student's test and ANOVA, with Tukey's multiple comparison test as post-hoc test, using GraphPad Prism 5. The data represent the mean value and SD. The difference was considered statistically significant at $p<0.05$.

\section{RESULTS}

\section{Sulfatide Inhibits HMGB1 and Pro-inflammatory Cytokines Release}

To study whether sulfatide treatment shows pro-inflammatory or anti-inflammatory characteristics, we analyzed the secretion level of a well-known DAMP molecule, HMGB1. When treated simultaneously, sulfatide exhibited an inhibitory effect in HMGB1 secretion without toxicity in a dose-dependent manner, as shown (Figure 1A, Supplementary Figure 1A). This phenotype was unique to sulfatide, and was not seen in its precursors, galactosylceramide, and ceramide (Supplementary Figure 1B). Further analysis using ligands of other extracellular TLRs shows complete inhibition of HMGB1 secretion (Supplementary Figure 1C). This indirectly suggests that the anti-inflammatory effect does not come from inhibiting the ligand-receptor interaction by acting as a competitive inhibitor or aggregating reagent against TLR ligands, since it is unlikely that a molecule can act as broad-range inhibitor or aggregating reagent against multiple TLR ligands with different characteristics. Next, the time point-dependent effect of sulfatide was studied to further investigate the mechanism of action (Figure 1B). Interestingly, sulfatide not only exhibited dose- and time-dependent manner in HMGB1 release suppression, but also removal of sulfatide only induced a slight increase-lower than the secretion level of negative control, neverthelessin HMGB1 secretion in 6 and 12 h-pretreatment samples. These results, combined with the results collected above,

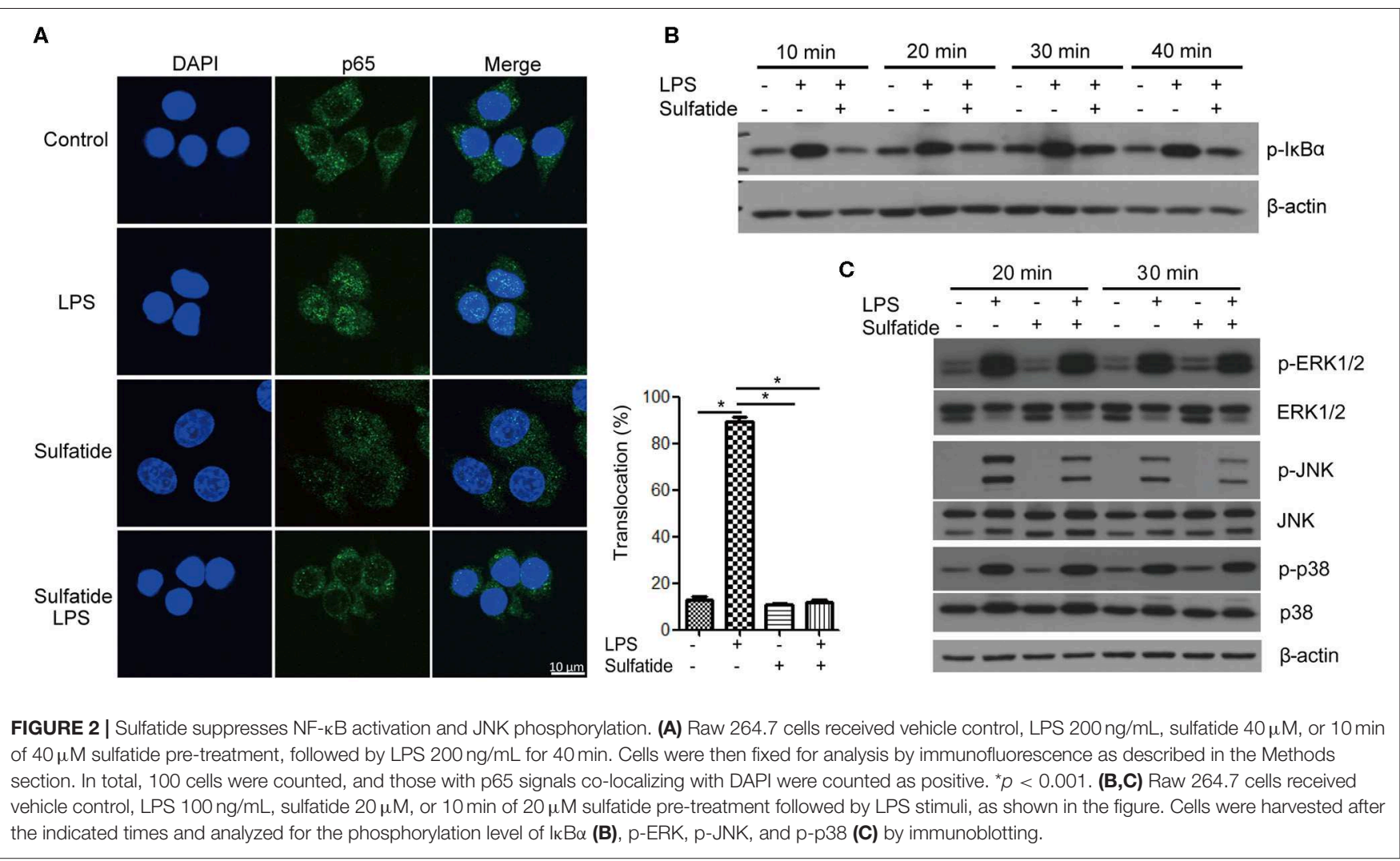


suggest that sulfatide is neither an aggregating reagent nor competitive inhibitor, nor a reversible non-competitive inhibitor of TLR ligands.

Although multiple points of inhibition are potentially available throughout the HMGB1 secretion pathway, they can be categorized into two large categories: initial signal transduction, and the release step. In order to clarify whether sulfatide affects the former or the latter, we treated Raw 264.7 cells with LPS or sulfatide and investigated HMGB1 localization via immunofluorescence microscopy (Figure 1C). Confocal microscopy images show sulfatide inhibits nuclear HMGB1 translocation to the cytoplasm caused by LPS stimulation. This indicates that the inhibition mechanism of sulfatide does not target the release of HMGB1 to the extracellular space itself, but the pathway that precedes HMGB1 translocation.

Previous reports state sulfatide to play a pro-inflammatory role in brain-resident immune cells (42). In order to confirm its anti-inflammatory characteristics shown within our experimental setup, we treated Raw 264.7 cells with vehicle control, LPS alone, or LPS stimuli after sulfatide pre-treatment (Figure 1D). Contrary to previous reports made with brainresident immune cells, sulfatide did not induce any significant secretion of pro-inflammatory cytokines, namely TNF- $\alpha$ and IL-6. Interestingly, a combination of LPS and sulfatide, however, did result in a significant decrease in the secretion levels of both TNF- $\alpha$ and IL-6, indicating that sulfatide indeed has an anti-inflammatory role in the peripheral immune system.
A

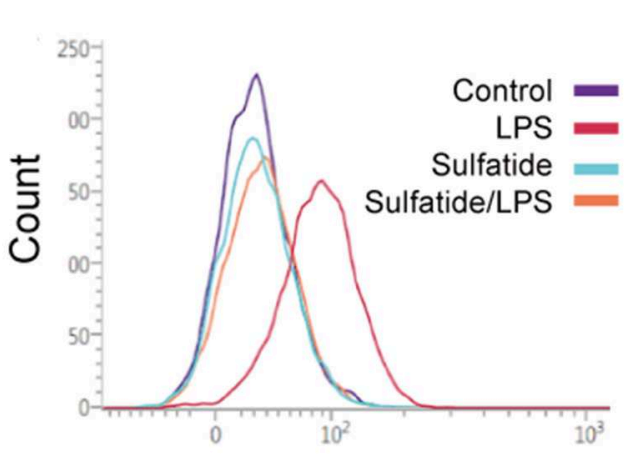

DCF-DA

B

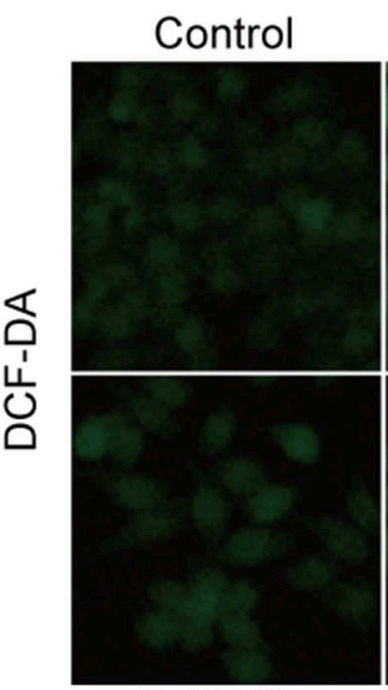

Sulfatide

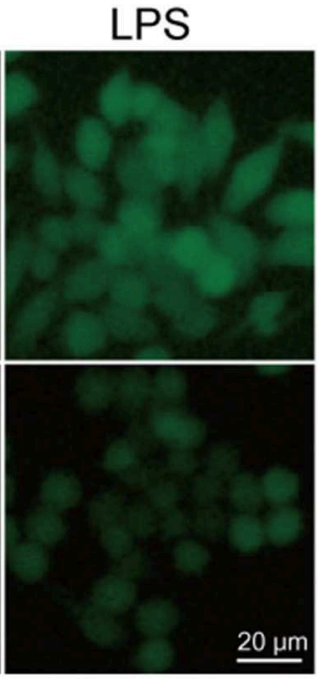

Sulfatide

LPS
C

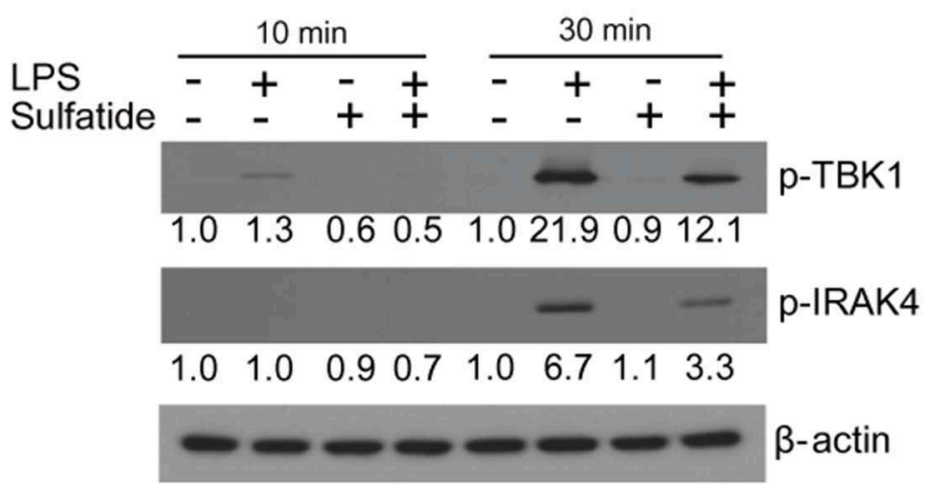

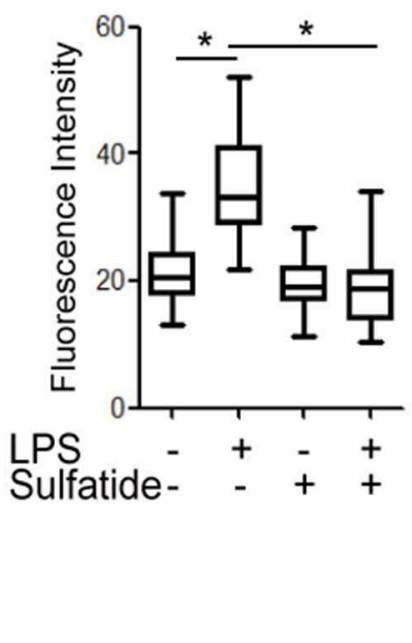

FIGURE 3 | Sulfatide down-regulates LPS-induced ROS production. Raw 264.7 cells were treated with $20 \mu \mathrm{M}$ sulfatide or vehicle control for 10 min prior to receiving LPS $100 \mathrm{ng} / \mathrm{mL}$, and were analyzed through (A) flow cytometry and (B) fluorescence microscopy. More than 150 cells were counted. ${ }^{*} p<0.001$. (C) Cells were pre-treated with vehicle control or $20 \mu \mathrm{M}$ sulfatide before treatment with $100 \mathrm{ng} / \mathrm{mL}$ LPS. Cells were lysed, and the samples were immunoblotted for $\mathrm{p}$-TBK1 and p-IRAK4. Numbers below the immunoblots represent the relative band intensity, obtained by densitometry analysis. Vehicle controls of each groups were considered as standards. 


\section{Sulfatide Down-Regulates NF-кB Signaling Pathway and JNK Phosphorylation}

The pathway most frequently associated with TLR signaling, NF- $\kappa \mathrm{B}$ signaling pathway, is a cascade of signaling molecules that results in the degradation of NF- $\kappa \mathrm{B}$ inhibitory molecules and the translocation of NF- $\mathrm{kB}$ to the nucleus, acting as a transcription factor. Concerning this pathway, we performed immunofluorescence microscopy, tracking the location of the p65 molecule, and immunoblotting of the Iк $\mathrm{B} \alpha$ molecule (Figures 2A,B). Our immunofluorescence data shows that NF$\kappa \mathrm{B}$ activation, signified by the translocation of $\mathrm{p} 65$, decreased when cells were pre-treated with sulfatide. Immunoblotting also indicated that phosphorylation of І $\kappa \mathrm{B} \alpha$, a crucial step that precedes its ubiquitination and degradation, significantly decreases when pre-treated with sulfatide.

Further analysis of the MAPKs within the TLR signaling pathway revealed specific kinases affected by sulfatide treatment. The phosphorylation levels of ERK, JNK, and p38 MAPK were analyzed via immunoblotting (Figure 2C). Immunoblots revealed that only the phosphorylation level of JNK, but not of ERK or p38, was decreased by pre-treatment with sulfatide. Overall, sulfatide blocks the NF-кB signaling pathway and JNK-mediated HMGB1 translocation.

\section{LPS-Mediated ROS Production Is Decreased by Sulfatide}

Since an alternate mechanism exists, where HMGB1 release can be triggered via LPS-TLR4 signaling through ROS production, we sought to measure the changes in the level of intracellular ROS in the presence/absence of sulfatide pre-treatment (Figures 3A,B). Flow cytometric analysis and measurement of relative fluorescence intensity both show a significant decrease in intracellular ROS levels in sulfatide pre-treated groups. Such a decrease in ROS levels can be accredited to the decreased phosphorylation of both TBK1 and IRAK4, molecules that play crucial roles in the regulation of NOX activity (Figure 3C). These results, paired with those presented in earlier experiments, propose that the point of inhibition, which sulfatide utilizes to suppress HMGB1 release is positioned higher in the signaling hierarchy.

\section{Sulfatide Hinders the Translocation of TLR4 Into Lipid Rafts}

We hypothesized that sulfatide, a well-known component of the cell membrane, may interfere with the lipid composition of the cell membrane, inhibiting its signaling pathways. Since

\section{A}
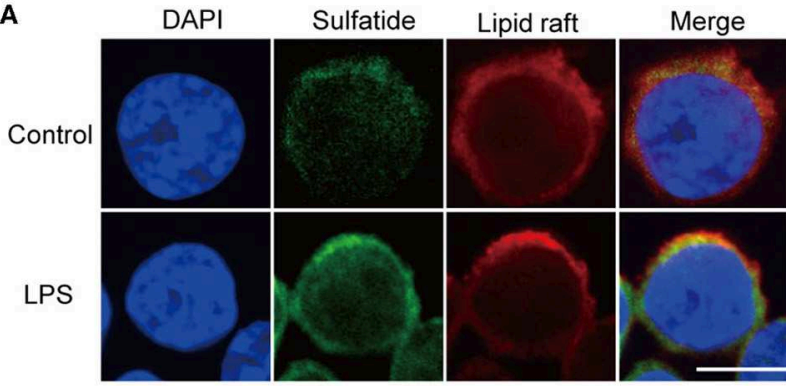

B

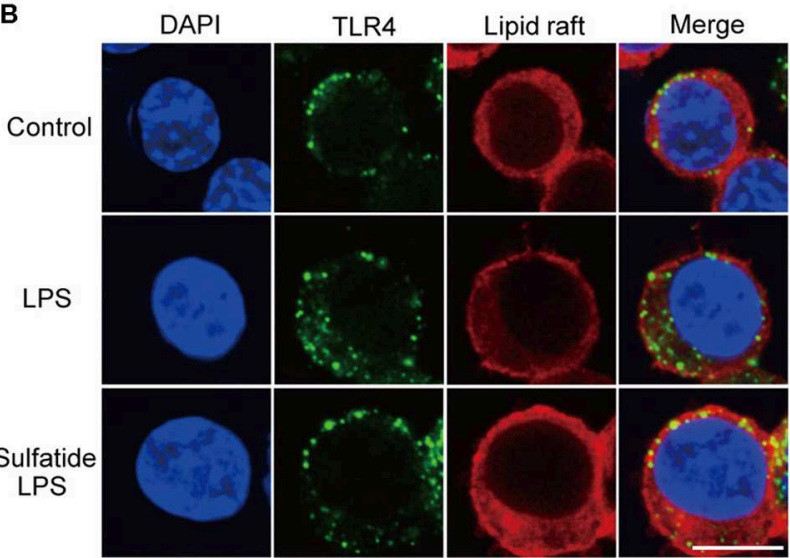

C
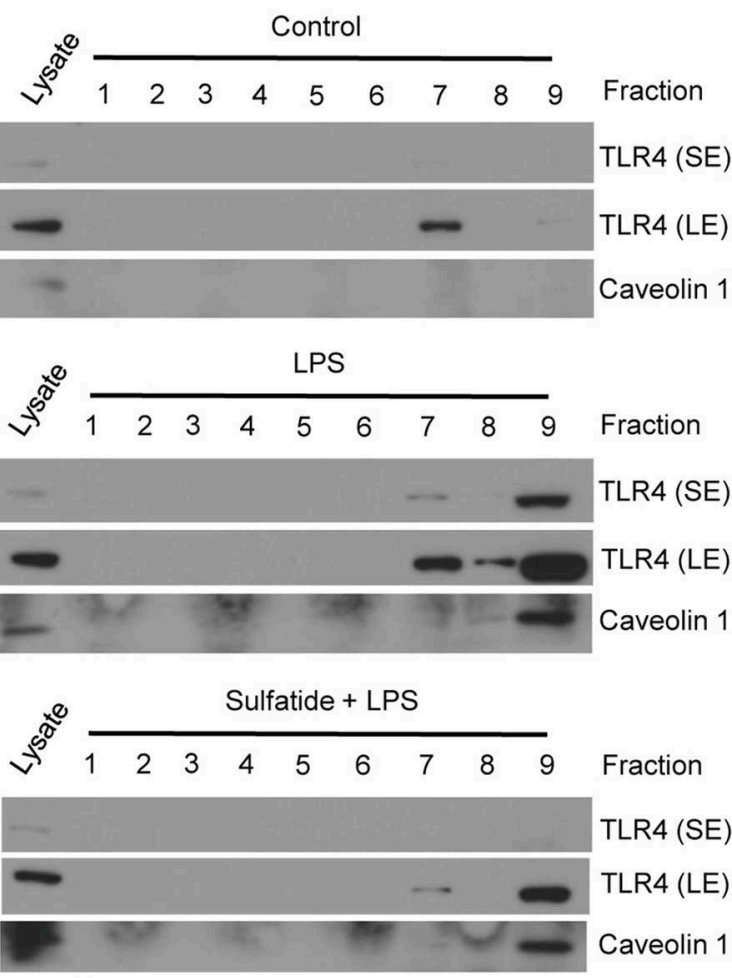

Fraction

TLR4 (SE)

TLR4 (LE)

Caveolin 1

FIGURE 4 | TLR4-lipid raft complex formation is reduced by sulfatide. (A) Raw264.7 cells were treated with $200 \mu \mathrm{M}$ of biotinylated sulfatide, with or without $1 \mu \mathrm{g} / \mathrm{mL}$ of LPS for $8 \mathrm{~min}$. Biotinylated sulfatide was stained with streptavidin-Alexa Fluor 488 and TLR4 with anti-rabbit-Alexa Fluor 549 , and the cells were prepared for confocal microscopy as described in the Methods section. (Scale bar : $10 \mu \mathrm{m}$ ) (B) Raw 264.7 cells were treated with vehicle control or $40 \mu \mathrm{M}$ of sulfatide for 10 min, before 8 min of vehicle control or $200 \mathrm{ng} / \mathrm{mL}$ of LPS treatment. (C) Raw 264.7 cells were identically treated as those in (B), and obtained samples were immunoblotted for TLR4 and caveolin 1. All membranes were immunoblotted under identical medical X-ray film for accurate comparison. (SE, Short Exposure; LE, Long Exposure). 
TLR4 requires its monomers to be localized within the lipid raft microdomains to form dimers, we sought to assess (1) whether sulfatide localizes to the lipid raft microdomains, and (2) whether sulfatide treatment curbs the localization of TLR4 to lipid rafts. Utilization of biotinylated sulfatide revealed the colocalization of sulfatide and lipid rafts (Figure 4A), indicating the possibility of direct involvement of sulfatide in the lipid raft machinery. Next, to observe the co-localization of TLR4 and lipid rafts, we treated cells with appropriate stimuli and were prepared for immunofluorescence. Results insinuated that sulfatide plays a role in significantly decreasing the localization of TLR4 into the lipid microdomains. Such findings were reinforced by subjecting the cells to identical conditions and fractionating the cell lysate for lipid rafts. Results showed significantly decreased co-localization of TLR4 within the lipid raft fractions, signified by caveolin-1, in sulfatide-treated groups. In summary, sulfatide was found to interfere with the localization of TLR4 within lipid rafts, decreasing the efficacy of TLR4 signaling (Figures 4B,C).

\section{Relase of HMGB1 Is Suppressed by Sulfatide in BMDM and the Murine Experimental Sepsis Model}

The effects of sulfatide in primary cells and in vivo murine models were measured. BMDMs of 8 weeks old female C57BL/6 mice were harvested and were subjected to the same stimuli used above (Figure 5A). BMDMs pre-treated with sulfatide showed significantly decreased HMGB1 secretion, compared to cells treated with LPS alone, congruent with data obtained with Raw 263.7 cells. Such conformity led us to induce an experimental septic shock by the means of a sub-lethal dose injection of LPS into the peritoneum of C57BL/6 mice. Measurement of serum HMGB1 level was taken from sera obtained from a total of 18 mice (Figure 5B). Serum HMGB1 level was significantly decreased in the groups pre-treated with sulfatide, compared to groups treated only with LPS (Figure 5B). These results show that sulfatide regulates the release of HMGB1, a late time point cytokine of sepsis, in the murine experimental sepsis model. Such decrease in the serum HMGB1 level is also reflected in the murine
A

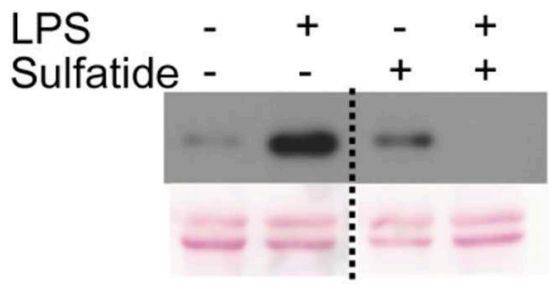

B

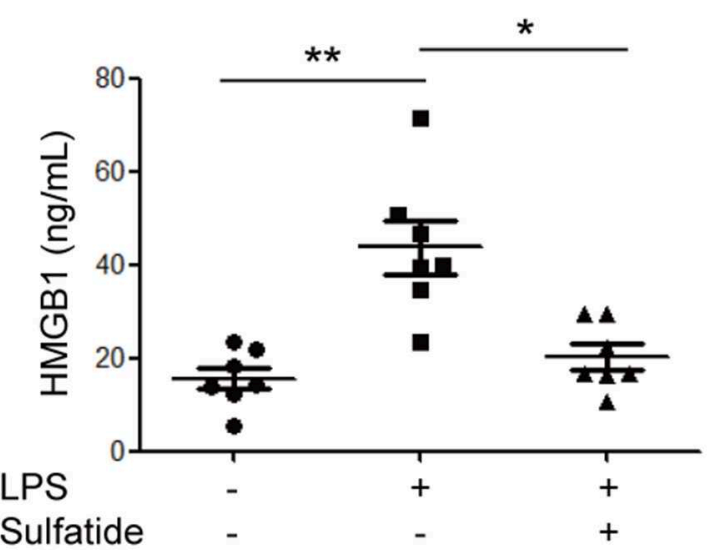

C

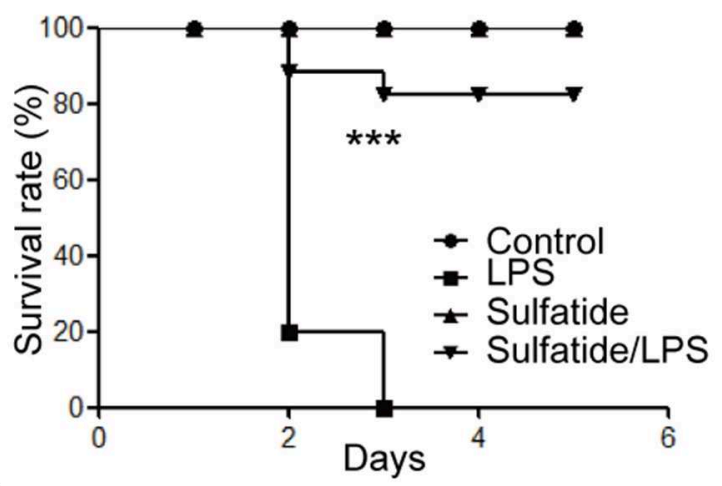

D

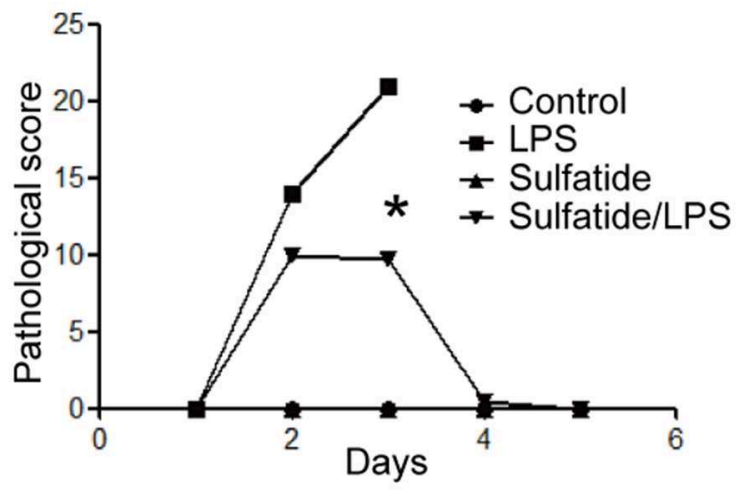

FIGURE 5 | Sulfatide decreases HMGB1 release in mouse BMDMs and the murine experimental sepsis model. (A) BMDMs were subjected to vehicle control, LPS $100 \mathrm{ng} / \mathrm{mL}$, and $10 \mathrm{~min}$ of $20 \mu \mathrm{M}$ sulfatide pre-treatment, followed by LPS $100 \mathrm{ng} / \mathrm{mL}$ for $24 \mathrm{~h}$. The dotted line indicates where different portion of the identical membrane have been presented together. (B) C57BL/6 mice (7 mice per group) were intraperitoneally injected with PBS, LPS, or sulfatide pre-treatment, followed by LPS injection, as discussed in the Methods section. Sera were harvested and prepared for ELISA to measure serum HMGB1 level. (C) C57BL/6 mice (5 mice per group) were subjected to a survival test against LPS-induced lethal septic shock. Two independent trials were completed, and the results were pooled for statistical analysis. (D) A pathological score was obtained from the mice described in (C). Mice from the second trial were used. ${ }^{\star} p<0.01,{ }^{\star \star} p<0.001,{ }^{\star \star \star} p<0.0001$. 
model injected with a lethal dosage of LPS, mimicking acute septic shock. Although showing the telltale signs of septic shock (decreased physical activity, shivering etc.), mice pre-injected with sulfatide before LPS injection experienced no death in the population, in contrary to those that received saline pre-injection (Figure 5C). Additionally, to accurately compare the severity of the septic shock and the effect of sulfatide in decreasing its severity, pathological scores were measured every $24 \mathrm{~h}$. Sulfatide pre-injected mice showed similar increase in pathological scores as the mice injected only with LPS for the first $24 \mathrm{~h}$; however, groups that only received LPS injection showed a continuous increase in pathological scores, whereas the scores of the sulfatide pre-injected group plateaued, followed by a decrease in the pathological score (Figure 5D). Generally, sulfatide successfully blocked the LPS-mediated HMGB1 release in sepsis, decreasing the level of serum HMGB1 and preventing severe symptoms and death caused by sepsis.

\section{DISCUSSION}

Our experiments showed sulfatide reducing HMGB1 secretion and cytosolic translocation upon LPS stimulation. Sulfatide decreased the activation of NF- $\mathrm{B}$ translocation into the nucleus, and inhibition of multiple kinases, such as JNK, IRAK4, and TBK1, was also seen throughout the experiment. JNK is a wellknown signaling molecule playing a crucial role in cellular stress conditions, and when activated, phosphorylated JNK can also alter the mitochondria to increase its ROS production significantly, creating a positive feedback loop (44). Mice expressing inactive mutant form of IRAK4 were found to be more susceptible to Listeria monocytogenes and Mycobacterium smegmatis systemic infections due to impaired induction of inducible nitric oxide synthase (iNOS) mRNA (45). Since TBK1 was also involved in mitophagic regulation of mitochondrial physiology and expression of iNOS mRNA during inflammatory assault, paired with the reduction of ROS production, we hypothesized that the inhibitory characteristics of sulfatide may come from the upper hierarchy $(46,47)$. Further experiments showed sulfatide was hindering the lipid raft-TLR4 interaction, thereby diminishing the TLR4 signaling pathway (Figure 6).

Based on our research, the possibility of exogenous sulfatide as regulator of lipid raft-receptor complex formation may be suggested in clinical scenarios, in addition to the experimental sepsis model provided within. Pathological action of angiotensin II, a potent vasoconstrictor which binds to the $\mathrm{AT}_{1}$ receptor, are ascribed to multiple vascular diseases, such as hypertension and secondary cardiac hypertrophy (48). $\mathrm{AT}_{1}$ receptors are reported to be associated with lipid rafts (49); thus, sulfatide can be used to alter the lipid composition of the microdomains to deter the pathology in angiotensin II-mediated hypertension patients. Moreover, the immunological synapse, crucial for $\mathrm{B} / \mathrm{T}$ cell activation, also depends on lipid raft formation (50-53), proposing a potential treatment strategy against autoimmune diseases such as rheumatoid arthritis, Type I diabetes, and multiple sclerosis (54-56) by blocking abnormal $\mathrm{B} / \mathrm{T}$ cell activation.

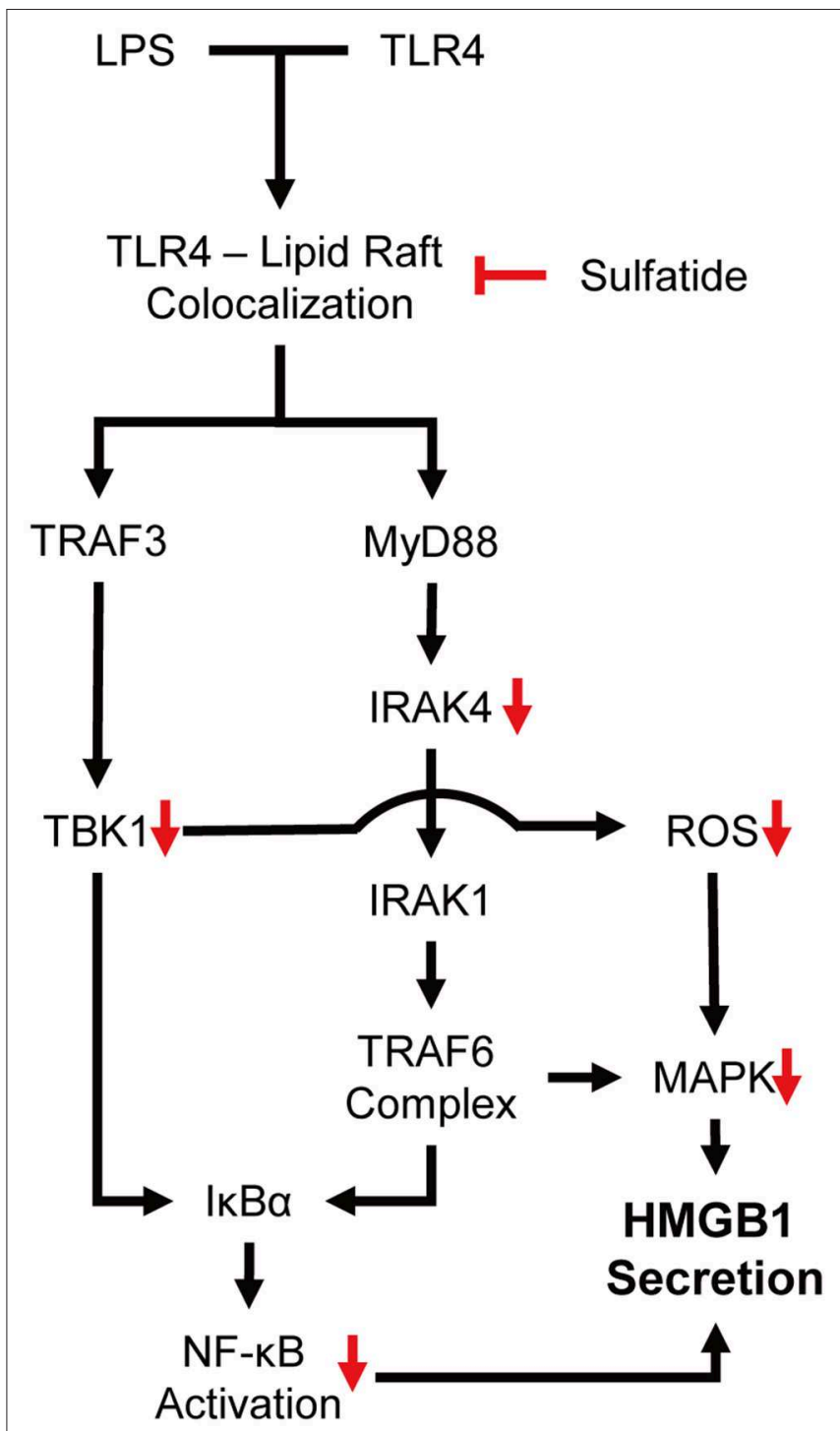

FIGURE 6 | Schematic summary of the proposed mechanism of action.

Sulfatide, however, has been reported as a possible autoantigen in multiple sclerosis and experimental autoimmune encephalomyelitis (EAE). Lipid microarrays showed specific antibodies against various lipids in the cerebrospinal fluid, including ones against sulfatide in the murine EAE model and in multiple sclerosis $(57,58)$. Kanter et al. also reported the increase in disease severity as the mice were immunized with sulfatide and myelin membrane proteins. A further role of sulfatide as a pro-inflammatory molecule in pathogenesis was discovered in autoimmune hepatitis (59). In contrast, the anti-inflammatory roles of sulfatide were also revealed in autoimmune neuritis and asthma, mediated by sulfatide-activated type II NKT cells $(37,60)$. These reports suggest that sulfatide can be a doubleedged sword, depending on the organ and pathological context, and that caution must be taken when attempting to adapt the "natural" form of sulfatide as a potential therapeutic agent. 
Further studies regarding the mechanism of action of sulfatide in the abovementioned pathologies should be pursued to minimize or ameliorate side effects, possibly by utilizing small molecules mimicking the action of sulfatide.

Our research was able to report the anti-inflammatory effect of sulfatide in the periphery, specify the kinases within the NF- $\kappa$ B and MAPK pathway affected by sulfatide, and elucidate its mechanism of action. Sulfatide, nevertheless, is naturally a mixture of varying lengths of carbon chain backbone; therefore, the sulfatide used in this experiment is close to its natural form but far from being homogenous. Such properties could control the accessibility of sulfatide isoforms to various molecules via steric hindrance and variation in affinity. The composition of sulfatide isoforms has been connected to MS prognosis, enabling physicians to differentiate remitting MS from progressive MS by studying the composition of sulfatide isoforms (61). Although we were able to discover sulfatide hampering the localization of TLR4 and lipid rafts in our research, the specific roles of each component of sulfatide are yet to be discovered. According to the composition sheet provided by the supplier, C24-related isoforms were dominant in the making of sulfatide. This may explain the difference in phenotype between our experiment and others, as we carefully suggest the difference stems from the variability of sulfatide composition, depending on the provider. Isaac et al. has reported the importance of $\mathrm{C} 18$ sulfatide in astrocyte functionality (62), whereas many researchers including Buschard et al. and Blomqvist et al. have reported the crucial role of the C16:0 isoform in diabetes mellitus $(63,64)$. Such reports describing distinct role of various sulfatide components could be used to aid in indirectly understanding the phenotype difference between our group and the others. We sought to specify the isoform solely responsible for the phenotype shown within C24related isoforms and C18 sulfatide, but to no avail (data not shown). Although we were not able to establish the isoform of sulfatide that is responsible for its properties, we were able to suggest that the mixture of C24-related isoforms and the C18 isoform that mimics the natural composition of sulfatide could also mimic its suppressive phenotype (Supplementary Figure 2). Fine-tuning the composition of specific isoforms by the means of supplementing the patients with sulfatide isoforms as needed may prove to be useful to alter the overall phenotype of sulfatide, further opening its therapeutic potential.

In conclusion, our study showed the effect of sulfatide in suppressing the secretion of HMGB1 under LPS stimulation,

\section{REFERENCES}

1. Goodwin GH, Sanders C, Johns EW. A new group of chromatin-associated proteins with a high content of acidic and basic amino acids. Eur J Biochem. (1973) 38: $14-9$.

2. Yoshida M, Makiguchi K, Chida Y, Shimura K. Unwinding of DNA by nonhistone protein HMG1 and HMG2. Nucleic Acids Symp Ser. (1984) 1984:181-4. and its potential as anti-sepsis treatment. We have also firstly described the mechanism of inhibition where sulfatide inhibits the localization of TLR4 within the lipid microdomains, nullifying LPS-TLR4 signaling cascade. Further investigations regarding the interaction of exogenous sulfatide with lipid microdomains, importance of sulfatide isoform composition in various inflammatory diseases, and in-depth studying of isoform lipid biology are necessary to pursue future therapeutic applications of sulfatide.

\section{DATA AVAILABILITY STATEMENT}

All datasets generated for this study are included in the article/Supplementary Material.

\section{ETHICS STATEMENT}

The animal study was reviewed and approved by Institutional Animal Care and Use Committee of the Yonsei Laboratory Animal Research Center.

\section{AUTHOR CONTRIBUTIONS}

HK performed the immunoblotting and ELISA analysis with regard to HMGB1 secretion and its mechanisms. $\mathrm{MH}$ and IP helped in the planning and execution of the animal experiments. $\mathrm{CP}$ aided with the overall experiments using BMDMs. MK and IP contributed to the detailed experimental planning. J-SS gave the final approval of the manuscript version and has overseen the project and provided overall guidance for the experimental design. All authors contributed to the article and approved the submitted version.

\section{FUNDING}

This research was supported by the National Research Foundation of Korea (NRF) funded by the Korean government (MEST) [2017R1A2B3006704, 2017R1D1A1B03028551, and 2019R1A6A1A03032869].

\section{SUPPLEMENTARY MATERIAL}

The Supplementary Material for this article can be found online at: https://www.frontiersin.org/articles/10.3389/fimmu. 2020.01305/full\#supplementary-material 
6. Tang D, Kang R, Livesey KM, Cheh C-W, Farkas A, Loughran P, et al. Endogenous HMGB1 regulates autophagy. J Cell Biol. (2010) 190:88192. doi: $10.1083 /$ jcb. 200911078

7. Lee H, Shin N, Song M, Kang U-B, Yeom J, Lee C, et al. Analysis of nuclear high mobility group box 1 (HMGB1)-binding proteins in colon cancer cells: clustering with proteins involved in secretion and extranuclear function. $J$ Proteome Res. (2010) 9:4661-70. doi: 10.1021/pr100386r

8. Scaffidi P, Misteli T, Bianchi ME. Release of chromatin protein HMGB1 by necrotic cells triggers inflammation. Nature. (2002) 418:191-5. doi: 10.1038/nature09475

9. Vande Walle L, Kanneganti T-D, Lamkanfi M. HMGB1 release by inflammasomes. Virulence. (2011) 2:162-5. doi: 10.4161/viru.2.2.15480

10. Wu C-X, Sun H, Liu Q, Guo H, Gong J-P. LPS induces HMGB1 relocation and release by activating the NF-kappaB-CBP signal transduction pathway in the murine macrophage-like cell line RAW264.7. J Surg Res. (2012) 175:88100. doi: 10.1016/j.jss.2011.02.026

11. Jiang W, Pisetsky DS. The role of IFN-alpha and nitric oxide in the release of HMGB1 by RAW 264.7 cells stimulated with polyinosinicpolycytidylic acid or lipopolysaccharide. J Immunol. (2006) 177:3337-43. doi: 10.4049/jimmunol.177.5.3337

12. Yang Z, Li L, Chen L, Yuan W, Dong L, Zhang Y, et al. PARP-1 mediates LPS-induced HMGB1 release by macrophages through regulation of HMGB1 acetylation. J Immunol. (2014) 193:6114-23. doi: 10.4049/jimmunol.1400359

13. Yu B, Wright SD. Catalytic properties of lipopolysaccharide (LPS) binding protein: Transfer of LPS to soluble CD14. J Biol Chem. (1996) 271:41005. doi: $10.1074 / \mathrm{jbc} .271 .8 .4100$

14. da Silva Correia J, Soldau K, Christen U, Tobias PS, Ulevitch RJ. Lipopolysaccharide is in close proximity to each of the proteins in its membrane receptor complex transfer from CD14 to TLR4 and MD-2. J Biol Chem. (2001) 276:21129-35. doi: 10.1074/jbc.M009164200

15. Lingwood D, Simons K. Lipid rafts as a membrane-organizing principle. Science. (2010) 327:46-50. doi: 10.1126/science.1174621

16. Ruysschaert JM, Lonez C. Role of lipid microdomains in TLRmediated signalling. Biochim Biophys Acta. (2015) 1848:18607. doi: 10.1016/j.bbamem.2015.03.014

17. Antoine DJ, Harris HE, Andersson U, Tracey KJ, Bianchi ME. A systematic nomenclature for the redox states of high mobility group box (HMGB) proteins. Mol Med. (2014) 20:135-7. doi: 10.2119/molmed.2014. 00022

18. Yang H, Wang H, Ju Z, Ragab AA, Lundbäck P, Long W, et al. MD-2 is required for disulfide HMGB1-dependent TLR4 signaling. J Exp Med. (2015) 212:5-14. doi: 10.1084/jem.20141318

19. Yang H, Antoine DJ, Andersson U, Tracey KJ. The many faces of HMGB1: molecular structure-functional activity in inflammation, apoptosis, and chemotaxis. J Leukoc Biol. (2013) 93:865-73. doi: 10.1189/jlb.1212662

20. Gunasekaran MK, Viranaicken W, Girard AC, Festy F, Cesari M, Roche R, et al. Inflammation triggers high mobility group box 1 (HMGB1) secretion in adipose tissue, a potential link to obesity. Cytokine. (2013) 64:10311. doi: 10.1016/j.cyto.2013.07.017

21. Urbonaviciute V, Meister S, Furnrohr BG, Frey B, Guckel E, Schett G, et al. Oxidation of the alarmin high-mobility group box 1 protein (HMGB1) during apoptosis. Autoimmunity. (2009) 42:305-7. doi: 10.1080/08916930902831803

22. Liu A, Fang $H$, Dirsch $O$, Jin $H$, Dahmen $U$. Oxidation of hmgbl causes attenuation of its pro-inflammatory activity and occurs during liver ischemia and reperfusion. PLOS ONE. (2012) 7:e35379. doi: 10.1371/journal.pone.0035379

23. Abdulmahdi W, Patel D, Rabadi MM, Azar T, Jules E, Lipphardt $\mathrm{M}$, et al. HMGB1 redox during sepsis. Redox Biol. (2017) 13:6007. doi: 10.1016/j.redox.2017.08.001

24. Huang W, Tang Y, Li L. HMGB1, a potent proinflammatory cytokine in sepsis. Cytokine. (2010) 51:119-26. doi: 10.1016/j.cyto.2010.02.021

25. Wang $H$, Ward MF, Sama AE. Targeting HMGB1 in the treatment of sepsis. Expert Opin Ther Targets. (2014) 18:25768. doi: 10.1517/14728222.2014.863876

26. Stevens NE, Chapman MJ, Fraser CK, Kuchel TR, Hayball JD, Diener KR. Therapeutic targeting of HMGB1 during experimental sepsis modulates the inflammatory cytokine profile to one associated with improved clinical outcomes. Sci Rep. (2017) 7:5850. doi: 10.1038/s41598-017-06205-z
27. Eckhardt M. The role and metabolism of sulfatide in the nervous system. $\mathrm{Mol}$ Neurobiol. (2008) 37:93-103. doi: 10.1007/s12035-008-8022-3

28. Levine M, Kornblatt MJ, Murray RK. Isolation and partial characterization of a sulfogalactoglycerolipid from rat brain. Can J Biochem. (1975) 53:679-89.

29. Ranscht B, Clapshaw PA, Price J, Noble M, Seifert W. Development of oligodendrocytes and Schwann cells studied with a monoclonal antibody against galactocerebroside. Proc Natl Acad Sci USA. (1982) 79:270913. doi: $10.1073 /$ pnas.79.8.2709

30. Ramakrishnan H, Hedayati KK, Lullmann-Rauch R, Wessig C, Fewou $\mathrm{SN}$, Maier $\mathrm{H}$, et al. Increasing sulfatide synthesis in myelin-forming cells of arylsulfatase a-deficient mice causes demyelination and neurological symptoms reminiscent of human metachromatic leukodystrophy. J Neurosci. (2007) 27:9482-90. doi: 10.1523/JNEUROSCI.2287-07.2007

31. Blomqvist $\mathrm{M}$, Osterbye $\mathrm{T}$, Månsson JE, Horn T, Buschard $\mathrm{K}$, Fredman P. Sulfatide is associated with insulin granules and located to microdomains of a cultured beta cell line. Glycoconj J. (2002) 19:403-13. doi: 10.1023/B:GLYC.0000004012.14438.e6

32. Blomqvist $\mathrm{M}$, Osterbye $\mathrm{T}$, Månsson J-E, Horn $\mathrm{T}$, Buschard $\mathrm{K}$, Fredman P. Selective lack of the C16:0 fatty acid isoform of sulfatide in pancreas of type II diabetic animal models. APMIS. (2003) 111:867-77. doi: 10.1034/j.1600-0463.2003.1110905.x

33. Buschard K, Blomqvist M, Osterbye T, Fredman P. Involvement of sulfatide in beta cells and type 1 and type 2 diabetes. Diabetologia. (2005) 48:195762. doi: 10.1007/s00125-005-1926-9

34. Buschard K, Bracey AW, McElroy DL, Magis AT, Osterbye T, Atkinson MA, et al. Sulfatide preserves insulin crystals not by being integrated in the lattice but by stabilizing their surface. J Diabetes Res. (2016) 2016:15. doi: 10.1155/2016/6179635

35. Merten M, Beythien C, Gutensohn K, Kuhnl P, Meinertz T, Thiagarajan P. Sulfatides activate platelets through P-selectin and enhance platelet and platelet-leukocyte aggregation. Arterioscler Thromb Vasc Biol. (2005) 25:25863. doi: 10.1161/01.ATV.0000149675.83552.83

36. Garcia J, Callewaert N, Borsig L. P-selectin mediates metastatic progression through binding to sulfatides on tumor cells. Glycobiology. (2007) 17:18596. doi: $10.1093 /$ glycob/cwl059

37. Zhang G, Nie H, Yang J, Ding X, Huang Y, Yu H, et al. Sulfatide-activated type II NKT cells prevent allergic airway inflammation by inhibiting type I NKT cell function in a mouse model of asthma. Am J Physiol Lung Cell Mol Physiol. (2011) 301:975-84. doi: 10.1152/ajplung.00114.2011

38. Sørensen JØ, Buschard K, Brogren C-H. The preventive role of type 2 NKT cells in the development of type 1 diabetes. APMIS. (2014) 122:16782. doi: 10.1111/apm.12140

39. Yang SH, Lee JP, Jang HR, Cha R -h, Han SS, Jeon US, et al. Sulfatide-reactive natural killer T cells abrogate ischemia-reperfusion injury. J Am Soc Nephrol. (2011) 22:1305-14. doi: 10.1681/ASN.2010080815

40. Maricic I, Sheng H, Marrero I, Seki E, Kisseleva T, Chaturvedi S, et al. Inhibition of type I natural killer $\mathrm{T}$ cells by retinoids or following sulfatidemediated activation of type II natural killer T cells attenuates alcoholic liver disease in mice. Hepatology. (2015) 61:1357-69. doi: 10.1002/hep.27632

41. Kwiecinski J, Rhost S, Löfbom L, Blomqvist M, Månsson JE, Cardell SL, et al. Sulfatide attenuates experimental Staphylococcus aureus sepsis through a CD1d-dependent pathway. Infect Immun. (2013) 81:111420. doi: 10.1128/IAI.01334-12

42. Jeon S-B, Yoon HJ, Park S-H, Kim I-H, Park EJ. Sulfatide, a major lipid component of myelin sheath, activates inflammatory responses as an endogenous stimulator in brain-resident immune cells. J Immunol. (2008) 181:8077-87. doi: 10.4049/jimmunol.181.11.8077

43. Shrum B, Anantha R V, Xu SX, Donnelly M, Haeryfar SMM, McCormick JK, et al. A robust scoring system to evaluate sepsis severity in an animal model. BMC Res Notes. (2014) 7:1-11. doi: 10.1186/1756-0500-7-233

44. Chambers JW, LoGrasso P V. Mitochondrial c-Jun N-terminal Kinase (JNK) signaling initiates physiological changes resulting in amplification of reactive oxygen species generation. J Biol Chem. (2011) 286:1605262. doi: 10.1074/jbc.M111.223602

45. Pattabiraman G, Murphy M, Agliano F, Karlinsey K, Medvedev AE. IRAK4 activity controls immune responses to intracellular bacteria Listeria monocytogenes and Mycobacterium smegmatis. J Leukoc Biol. (2018) 104:811-20. doi: 10.1002/JLB.2A1117-449R 
46. Kulsantiwong P, Pudla M, Srisaowakarn C, Boondit J, Utaisincharoen P. Pam2CSK4 and Pam3CSK4 induce iNOS expression via TBK1 and MyD88 molecules in mouse macrophage cell line RAW264.7. Inflamm Res. (2017) 66:843-53. doi: 10.1007/s00011-017-1063-1

47. Moore AS, Holzbaur ELF. Dynamic recruitment and activation of ALS-associated TBK1 with its target optineurin are required for efficient mitophagy. Proc Natl Acad Sci USA. (2016) 113:E3349E58. doi: 10.1073/pnas.1523810113

48. Crowley SD, Gurley SB, Herrera MJ, Ruiz P, Griffiths R, Kumar AP, et al. Angiotensin II causes hypertension and cardiac hypertrophy through its receptors in the kidney. Proc Natl Acad Sci USA. (2006) 103:1798590. doi: 10.1073/pnas.0605545103

49. Balla A, Tóth DJ, Soltész-Katona E, Szakadáti G, Erdélyi LS, Várnai P, et al. Mapping of the localization of type 1 angiotensin receptor in membrane microdomains using bioluminescence resonance energy transferbased sensors. J Biol Chem. (2012) 287:9090-9. doi: 10.1074/jbc.M111.2 93944

50. Kallikourdis M, Trovato AE, Roselli G, Muscolini M, Porciello N, Tuosto L, et al. Phosphatidylinositol 4-Phosphate 5-Kinase $\beta$ controls recruitment of lipid rafts into the immunological synapse. J Immunol. (2016) 2016:1501788. doi: 10.4049/jimmunol.1501788

51. Marwali MR, MacLeod MA, Muzia DN, Takei F. Lipid rafts mediate association of LFA-1 and CD3 and formation of the immunological synapse of CTL. J Immunol. (2004) 173:2960-7. doi: 10.4049/jimmunol.173. 5.2960

52. Varshney P, Yadav V, Saini N. Lipid rafts in immune signalling: current progress and future perspective. Immunology. (2016) 149:13-24. doi: 10.1111/imm.12617

53. Zumerle S, Molon B, Viola A. membrane rafts in $\mathrm{t}$ cell activation: a spotlight on CD28 costimulation. Front Immunol. (2017) 8:1467. doi: 10.3389/fimmu.2017.01467

54. Badenhoop K, Boehm BO. Genetic susceptibility and immunological synapse in type 1 diabetes and thyroid autoimmune disease. Exp Clin Endocrinol Diabetes. (2004) 112:407-415. doi: 10.1055/s-2004-821206

55. Rodríguez-Fernández JL. Antigen presentation by dendritic cells in rheumatoid arthritis. Curr Top Med Chem. (2013) 13:712-9. doi: 10.2174/1568026611313060004

56. Shapiro S, Galboiz Y, Lahat N, Kinarty A, Miller A. The "immunologicalsynapse" at its APC side in relapsing and secondary-progressive multiple sclerosis: modulation by interferon-beta. J Neuroimmunol. (2003) 144:11624. doi: 10.1016/j.jneuroim.2003.08.002
57. Kanter JL, Narayana S, Ho PP, Catz I, Warren KG, Sobel RA, et al. Lipid microarrays identify key mediators of autoimmune brain inflammation. Nat Med. (2006) 12:138-43. doi: 10.1038/nm1344

58. Halmer R, Walter $\mathrm{S}$, Faßbender K. Sphingolipids: Important players in multiple sclerosis. Cell Physiol Biochem. (2014) 34:111-8. doi: 10.1159/000362988

59. Sebode M, Wigger J, Filpe P, Fischer L, Weidemann S, Krech T, et al. Inflammatory phenotype of intrahepatic sulfatide-reactive type II NKT cells in humans with autoimmune hepatitis. Front Immunol. (2019) 10:1065. doi: 10.3389/fimmu.2019.01065

60. Wang SX, Yang CL, Zhang M, Zhang P, Liu RT, Zhang N, et al. Sulfatides ameliorate experimental autoimmune neuritis by suppressing Th1/Th17 cells. J Neuroimmunol. (2019) 326:55-61. doi: 10.1016/j.jneuroim.2018.11.008

61. Novakova L, Singh AK, Axelsson M, Ståhlman M, Adiels M, Malmeström C, et al. Sulfatide isoform pattern in cerebrospinal fluid discriminates progressive MS from relapsing-remitting MS. J Neurochem. (2018) 146:32232. doi: $10.1111 /$ jnc. 14452

62. Isaac G, Pernber Z, Gieselmann V, Hansson E, Bergquist J, Månsson JE. Sulfatide with short fatty acid dominates in astrocytes and neurons. FEBS J. (2006) 273:1782-90. doi: 10.1111/j.1742-4658.2006.05195.x

63. Buschard K, Blomqvist M, Månsson JE, Fredman P, Juhl K, Gromada J. C16:0 Sulfatide inhibits insulin secretion in rat $\beta$-cells by reducing the sensitivity of KATP channels to ATP inhibition. Diabetes. (2006) 55:282634. doi: $10.2337 / \mathrm{db} 05-1355$

64. Blomqvist M, Carrier M, Andrews T, Pettersson K, Månsson JE, Rynmark $\mathrm{BM}$, et al. In vivo administration of the C16:0 fatty acid isoform of sulfatide increases pancreatic sulfatide and enhances glucose-stimulated insulin secretion in Zucker fatty (fa/fa) rats. Diabetes Metab Res Rev. (2005) 21:158-66. doi: 10.1002/dmrr.519

Conflict of Interest: The authors declare that the research was conducted in the absence of any commercial or financial relationships that could be construed as a potential conflict of interest.

Copyright (c) 2020 Kim, Han, Park, Park, Kwak and Shin. This is an open-access article distributed under the terms of the Creative Commons Attribution License (CC $B Y)$. The use, distribution or reproduction in other forums is permitted, provided the original author(s) and the copyright owner(s) are credited and that the original publication in this journal is cited, in accordance with accepted academic practice. No use, distribution or reproduction is permitted which does not comply with these terms. 